\title{
Robust Multisensor Prediction of Drought-Induced Soybean Yield Anomalies in Argentina
}

This paper was downloaded from TechRxiv (https://www.techrxiv.org).

\section{LICENSE}

CC BY 4.0

SUBMISSION DATE / POSTED DATE

$16-12-2021 / 21-12-2021$

\section{CITATION}

Maas, Martin D.; Salvia, Mercedes; Spennemann, Pablo; Fernandez-Long, María Elena (2021): Robust Multisensor Prediction of Drought-Induced Soybean Yield Anomalies in Argentina. TechRxiv. Preprint. https://doi.org/10.36227/techrxiv.17232371.v1

$\mathrm{DOI}$ 


\title{
Robust Multisensor Prediction of Drought-Induced Soybean Yield Anomalies in Argentina
}

\author{
Martin D. Maas, Mercedes Salvia Member, IEEE,, Pablo C. Spennemann, María Elena Fernandez-Long
}

\begin{abstract}
A multi-sensor method for the prediction of droughtinduced agricultural impact is put forth in this paper. The input data considered includes MODIS NDVI and LST, ESA-CCI Soil Moisture, and CHIRPS rain data, which is processed at the department level in a large and sparsely monitored cropland in Argentina. As ground truth, we have employed departmentscale crop losses estimated by an annual agricultural census. In particular, the period under consideration (2001-2019) includes five severe drought events where soybean production in the area was considerably affected. The proposed method is based on Lasso-regression of corresponding rank values of the satellite data to the relative yield anomalies. Importantly, the proposed methodology is robust to extreme drought events. In addition, an associated early warning classification method results in higher than $67 \%$ overall accuracy for every year of the period under consideration, up to three months before the harvest. The proposed methodology offers a valuable method for the prediction of agricultural drought impact, and should be especially valuable in sparsely monitored regions of the world.
\end{abstract}

\section{INTRODUCTION}

Drought is among the most costly and least understood natural hazards [1], [2]. In particular, agricultural drought can severely compromise productivity [3], and can also generate an economic cascading effect on other sectors [4]. It is therefore of great importance to continuously improve the monitoring and prediction capabilities of agricultural drought.

A great variety of drought indices have been proposed over time [5]. The selection of the most suitable index depends on the application, and also hinges on the availability on a variety of data. In particular, over regions with poor rain-gauge coverage and where crops are mainly rainfed, remote sensing is a fundamental tool for monitoring agricultural drought. However, it is well known that no single remote sensing product can capture the year-to-year spatial variation of yield reductions associated with drought conditions [6], which motivates the development of combined drought indices.

A combined index integrating Land Surface Temperature (LST) and the Enhanced Vegetation Index (EVI) was proposed in [7], and denoted the Temperature Vegetation Dryness Index (TVDI). This index has been employed to predict soybean and wheat yields with good performance from 2 to 3 months prior to the harvest (i.e. January and February). This model was implemented employing regional-averages, for two different areas of the Argentine Pampas for each crop.

Remotely sensed soil moisture, in addition to NDVI and LST, forms the basis of the Soil Moisture Agricultural Drought

Martín D. Maas is with CONICET and SMN, Mercedes Salvia is with CONICET, Pablo C. Spenneman is with CONICET, SMN and UNTREF, María Elena Fernandez-Long is with FAUBA
Index (SMADI), proposed in [8]. In [9], the capability of the SMADI index to detect droughts was found to outperform precipitation-based indices like Standardized Precipitation Index (SPI) and Standardized Precipitation Evapotranspiration Index (SPEI), for both hit rates and false alarms, when using agricultural emergency declarations by the Argentine government as ground truth.

Different statistical techniques have been proposed in the literature to integrate various sources of data for yield prediction. For example, [10] studies the combination of climate data with remote sensing indicators, and compares various techniques to improve wheat yield predictions over Australia. Their results show, in particular, that of the proposed methods, the most robust under extreme drought events is the Lasso [11] regression [10, Figure 8].

The present study focuses on the quantitative assessment of soybean yield anomalies at the department scale, using a robust statistical approach based on a Lasso regression applied to the rank values of remote sensing data for precipitation, soil moisture, surface temperature, and vegetation greenness. It should noted that department scale is the most relevant administrative level at which a number of decisions related to emergency response take place, such as disaster compensation [12]. Also, our target metric is the relative yield anomalies per department (i.e. percentage loss), which different productive regions with high spatial heterogeneity of average yields comparable. The relative yield assessment is also a relevant metric for the individual producer, and moreover, it forms the basis of the emergency compensation law in Argentina.

\section{STUDY AREA AND DATA}

\section{A. Study area}

Argentina contains vast, fertile, and sparsely monitored croplands, responsible for a significant share of the global food trade. Grown almost exclusively under rainfed conditions [13], crop yields strongly depend on precipitation variability. Consequently, the occurrence of drought events has a significant impact on crop production. With Argentina's National Weather Service running a sparse network of 125 weather stations with an average density of one every $22,240 \mathrm{Km}^{2}$, remote sensing is expected to play a significant role in the rapid assessment of the region at a higher resolution level, such as the department level $\left(7,110 \mathrm{Km}^{2}\right.$ in average).

The most important crop grown in the region is soybean, with an average of $16.85 \mathrm{M} \mathrm{Ha}\left(168,850 \mathrm{Km}^{2}\right)$ of sowed area based on the last three agricultural campaigns [14]. For the present study, we have selected the departments where 


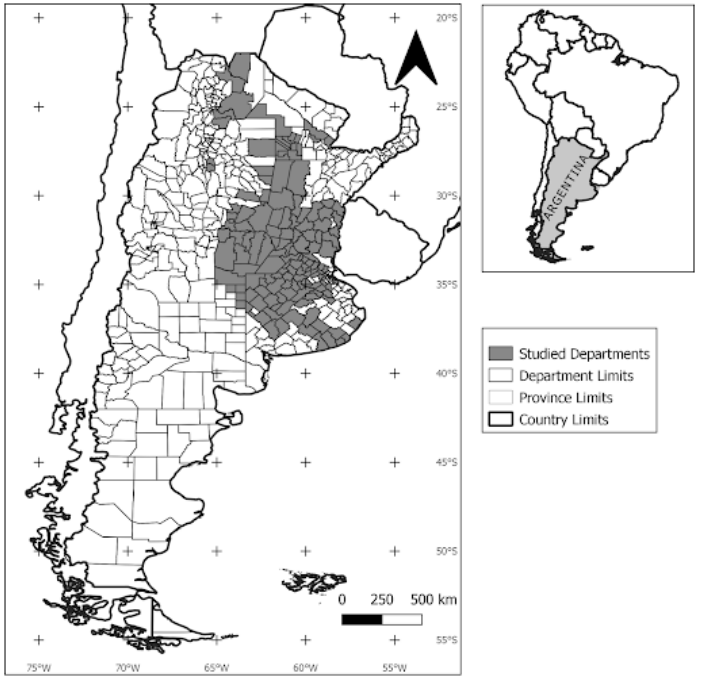

Fig. 1. Study area: selected departments with soybean yields consistently above $1.5 \mathrm{tn} / \mathrm{h}$

soybean yields have been consistently higher than $1.5 \mathrm{tn} / \mathrm{Ha}$ during the period under consideration, which resulted in the 144 departments $\left(644,391 \mathrm{Km}^{2}\right)$ shown in Figure 1. It should be noticed that the selected departments show a high spatial variation in average yields, which include a large highly productive area (as high as $4 \mathrm{tn} / \mathrm{Ha}$ ) known as the Argentine Pampas.

\section{B. Remote sensing products}

Based on data availability for the period under consideration and a preliminary accuracy assessment, we opted to incorporate the following remote sensing data sources: CHIRPS [15] for rain data, ESACCI v5.2 passive soil moisture product [16], [17], MODIS NDVI (MYD13C2 and MOD13C2), and MODIS LST (MOD11C3 and MYD11C3). The corresponding monthly data products were selected and averaged over each department. It should be highlighted that, for operational purposes, higher-frequency versions of the corresponding data products can be employed.

\section{Ground truth}

Soybean crop yield data was obtained from Argentina's Ministry of Agriculture [14]. The methodology to produce such data is based on an agricultural census, which has been produced on an annual basis since 1969 at the department scale. For the purpose of the present work, data for the 20012019 period was considered (see Figure 2).

\section{Statistical Modelling}

The proposed approach to multi-sensor prediction of agricultural drought is based on a number of procedures comprising the yield data, the satellite data products, and the choice of regression and classification models.

As a first step, it was observed that soybean yield data presents an ascending temporal trend during the period under consideration, and also very clear spatial patterns of higher or

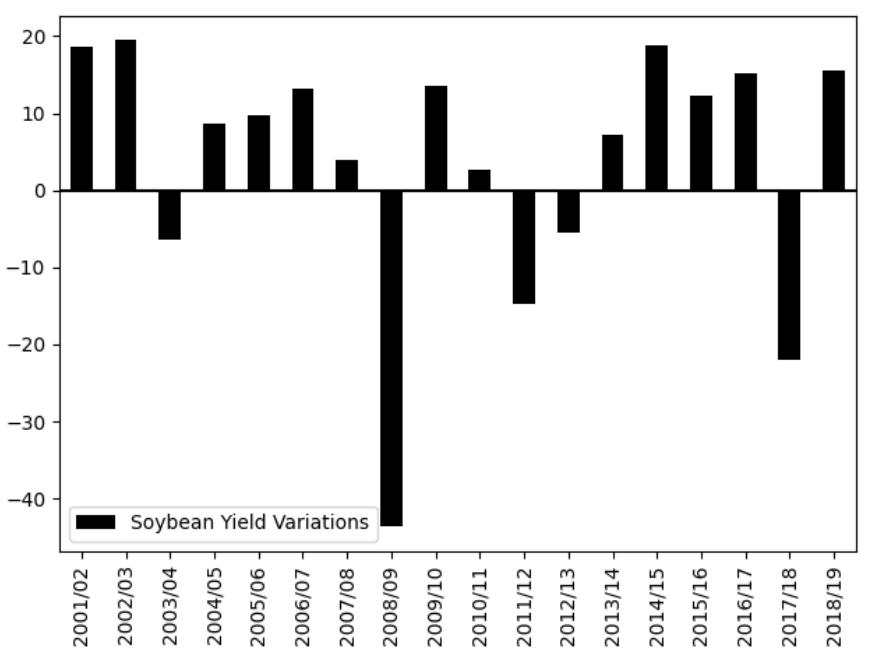

Fig. 2. Average yield variation vs median of previous 7 years (2001-2019).

lower yields, mostly related to soil types. In order to exclude the influence of such factors from the analysis, the yield data was detrended and normalized. In order to achieve this, a reference yield value, consisting of the median yield of the previous 7 years, was considered for each department. Relative yield gain/losses with respect to each reference value were subsequently expressed as a percentage.

As a second step, the multi-sensor data was pre-processed by retaining its ordinal information, rather than using absolute values, or normalizations based on standard deviation estimates (such as the popular SPI for rain data). In particular, the percentile with respect to the same month of the corresponding historical record was computed for each department. Not only this makes the different data sources comparable, but also reduces the impact of monotonic non-linearities.

As a third step, we applied the Lasso [11] to the resulting data. Lasso is an advanced linear model with a built-in variable selection method, which leads to models that are simple to interpret. As a consequence, it enjoys a reduced chance of over-fitting. Random Forest regression models were employed for comparison purposes.

Defining $q$ for each department, $y$ for yields, and $w_{j}^{(i)}$ and $d_{j}^{(i)}(q)$ and as the corresponding weights and (ordinal) data points of source $j$ at time $n$, our model can be expressed as:

$$
y(q) \sim \sum_{j=1}^{J} \sum_{n=1}^{N} w_{j}^{(n)} d_{j}^{(n)}(q)
$$

\section{A. Classification and Early Warning}

Any regression model can be employed as a classifier by applying a threshold. We have selected $20 \%$ as a representative threshold of predicted losses to discriminate drought vs nodrought conditions:

$$
f(p)=\left\{\begin{array}{l}
1 \text { if } p<-20 \\
0 \text { if } p>-20
\end{array}\right.
$$

The relevant time period was chosen on the basis of the crop cycle (October to March). Early warning indicators can be 
obtained simply by training the model using fewer months of data (i.e. setting $N=2,3,4,5$ in eq. [1]).

\section{B. Performance Metrics}

In order to evaluate the use of the proposed classification as an early warning system, several performance metrics were considered: overall accuracy (the ratio of departments that were correctly classified either as drought or non-drought events), the false-positive rate (ratio of departments that did not have a drought but were classified as if they did), and falsenegative rate (ratio of departments classified as non-drought that actually suffered from a drought).

To assess the accuracy of the proposed approach, a leaveone-year-out cross-validation study was performed. The average performance is reported, and, crucially, the worstperforming year results, which usually coincide during extreme events.

\section{RESUlts AND DiscUSSION}

\section{A. Obtained Lasso Coefficients}

Table I shows the obtained Lasso coefficients, which selects a subset of meaningful non-zero coefficients. In particular, the model returns non-zero values for the CHIRPS percentile with higher positive values for December-January, months which coincide with the critical period of water intake for this crop. Other meaningful information is the NDVI percentile showing the maximum positive coefficient value in January, followed by March and February. The low negative LST values indicates that yields decrease with high average surface temperatures. Soil moisture (SM) values were selected by the model only for the month of December. It is interesting to note the low number of non-zero coefficients for this variable. It should be noted that LST and SM have a negative correlation [18] and that the model could be selecting LST values as a SM proxy (i.e. in October and November).

TABLE I

LASSO COEFFICIENTS FOR SOYBEANS

\begin{tabular}{lrrrrrr}
\hline & Oct & Nov & Dec & Jan & Feb & Mar \\
\hline chirps & - & 0.87 & 7.15 & 2.88 & 0.96 & 2.06 \\
ndvi & 0.4 & 2.00 & - & 11.38 & 3.42 & 5.05 \\
smoist & - & - & 3.68 & - & - & - \\
lst & -1.99 & -7.72 & - & - & -5.89 & - \\
\hline
\end{tabular}

\section{B. Cross-Validation Analysis}

As shown in Figure 3, an analysis of separate training and test data shows a mean absolute error (MAE) of $14.46 \%$ for the training dataset and $16.04 \%$ for the test dataset. Additional regressions methods such as the popular Forest Regression model were also tested. Such models were able to reduce the MAE in the training datasets to as low as 5\%, but their generalization to the testing dataset didn't improve the performance of the Lasso (figure not shown). This is in line with [19], where a comparison of the Lasso with various nonlinear neural-network did not outperform Lasso, except for the proposed YieldNet model).

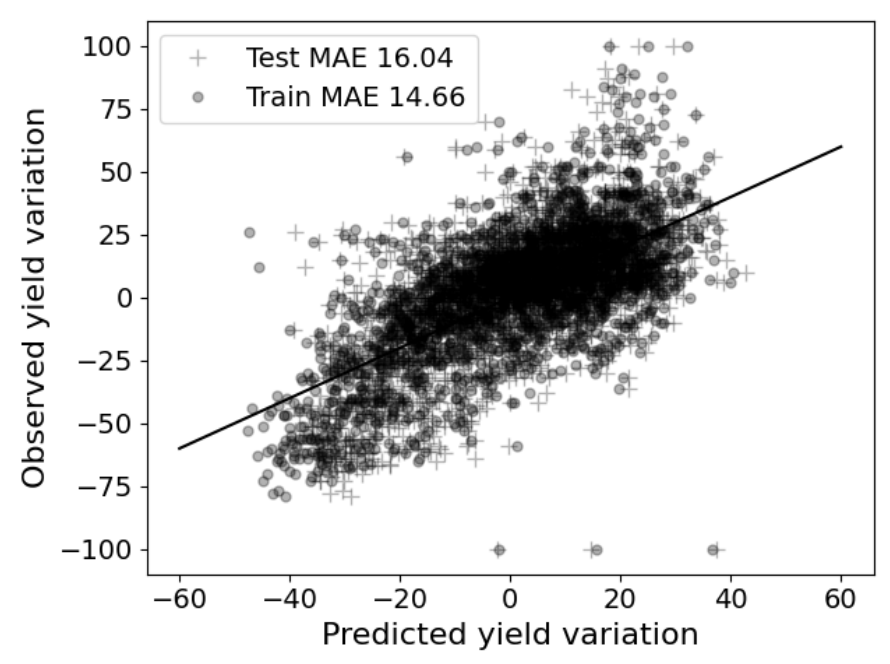

Fig. 3. Predicted vs observed yield variations, cross-validation analysis.

The absolute errors obtained through the method described in this study are similar to the $12 \%$ and $13 \%$ average yield error estimates for soybean found by [7] for two subregions (total of 72,508 $\mathrm{Km}^{2}$ ) within the Argentine Pampas, and four agricultural campaings containing different events ranging from severe drought to wet conditions. The present study manages to obtain a similar accuracy in spite of the substantially higher resolution and the wider area under consideration, which includes all the departments with moderate to high soybean yields in Argentina.

As for higher-resolution studies, in [19], a simultaneous corn and soybean yield prediction using convolutional neural networks, for the United States' corn belt region. They used MODIS LST and reflectance data between 2004 and 2018, over 1132 counties for corn and 1076 counties for soybean. When testing their methodology over 3 specific non-drought years they document an average yield prediction MAE of $8.74 \%$ (corn) and $8.70 \%$ (soybean). The lower MAE values obtained should be analyzed taking into consideration the absence of extreme drought events during the testing period. When including extreme events, as shown by [10] and in the present study, the errors are expected to be higher.

Figure 4 shows the performance of the classification approach, using various metrics. In particular, the average performance reaches a value of $88 \%$ by the end of February, and $85 \%$ at the end of January. However, taking the most conservative approach, a more stringent metric should be adopted, which is the classification accuracy of the worstperforming year. In this case, the classification accuracy drops to $69 \%$ for February (2017), 71\% for January (2008), and 67\% for December (2008). The analysis also shows that attempting a clasification with more than three months before the harvest, while still enjoying an average classification accuracy of $79 \%$ throughout the period under study, can be unreliable during extreme drought events, such as the one which took place during 2008-2009, where a 37\% accuracy was obtained, and where most of the error originated in a 58\% false-negative rate. If we compare these results with the ones obtained by 

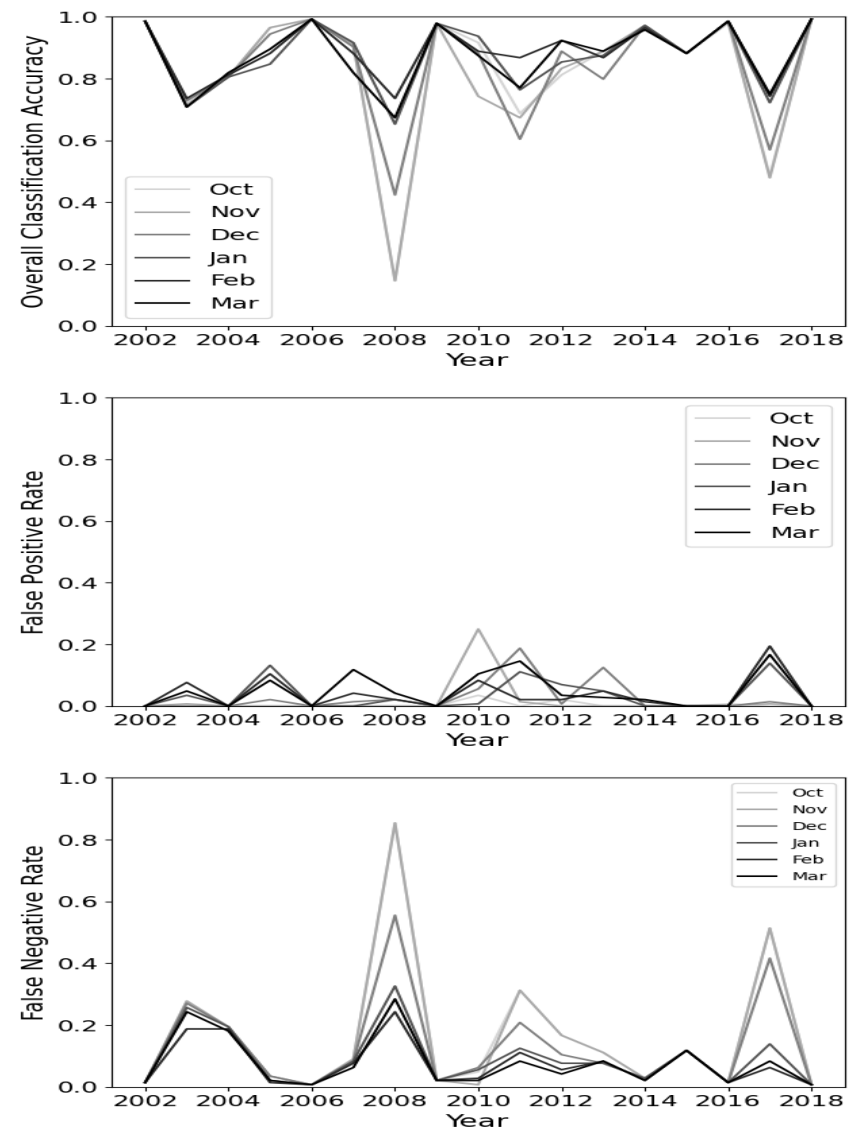

Fig. 4. Classification accuracy for the diferent crops under consideration, evaluated via cross-validation

[9], we can see that Lasso obtains a better average Overall Accuracy and False Positive Rate, and similar False Negative rates if input data includes at least that of December.

\section{CONCLUSION}

In this study, a statistical methodology for predicting soybean yield anomalies using different remote sensing products at a department scale was evaluated over Argentina. This methodology proved to be robust to extreme drought events that occurred during the 2001-2019 period. An early warning classification with $67 \%$ accuracy in the worst-performing year was obtained, using data up to three months before the harvest. At the same time, the average classification accuracy reaches $88 \%$ with data up to one month before the harvest.

A quantitative comparison against other studies was not completely straightforward, as there were differences in the selected metrics (i.e. absolute yields vs relative yield anomalies) and error metrics (average performance vs performance during extreme events). The proposed methodology provides a valuable tool for soybean yield forecasting at the department level in Argentina, and is suitable to inform the needs of emergency response, and for sparsely monitored areas that display heterogeneous yields. An implementation of a nearreal-time version of the proposed approach is straightforward, and currently in progress.

\section{ACKNOWLEDGMENTS}

The present study was partially supported by ANPIDTI PICT-2019-03639 and PICT-2017-1406, and the SISSA project (BID and by EUROCLIMA+18).

\section{REFERENCES}

[1] U. Nations, "Global assessment report on disaster risk reduction." https://www.preventionweb.net/publications/view/78456.

[2] D. A. Wilhite and M. H. Glantz, "Understanding: the drought phenomenon: The role of definitions," Water International, vol. 10, no. 3, pp. 111-120, 1985.

[3] A. Mishra and V. Singh, "A review of drought concepts," Journal of hydrology, vol. 391, no. 1-2, pp. 202-216, 2010.

[4] F. Bert, de M. Estrada, G. Naumann, R. Negri, G. Podestá, M. Skansi, P. Spennemann, and M. Quesada, "The 2017-18 drought in the argentine pampas-impacts on agriculture," United Nations Office for Disaster Risk Reduction (2021). GAR Special Report on Drought, 2021.

[5] M. Svoboda and B. Fuchs, "World meteorological organization (wmo) and global water partnership (gwp), 2016: Handbook of drought indicators and indices," Integrated Drought Management Programme (IDMP), Integrated Drought Management Tools and Guidelines. Series, vol. 2.

[6] M. Anderson, C. Z. P. Sentelhas, C. Hain, K. Semmens, M. Yilmaz, F. Gao, J. Otkin, and R. Tetrault, "The evaporative stress index as an indicator of agricultural drought in brazil: An assessment based on crop yield impacts," Remote Sensing of Environment, vol. 174, pp. 82-99, 2016.

[7] M. Holzman, R. Rivas, and M. Piccolo, "Estimating soil moisture and the relationship with crop yield using surface temperature and vegetation index," International Journal of Applied Earth Observation and Geoinformation, vol. 28, pp. 181-192, 2014.

[8] N. Sánchez, A. González-Zamora, M. Piles, and J. Martínez-Fernández, "A new soil moisture agricultural drought index (smadi) integrating modis and smos products: A case of study over the iberian peninsula," Remote Sensing, vol. 8, no. 4, 2016.

[9] M. Salvia, N. Sánchez, M. Piles, R. Ruscica, A. González-Zamora, E. Roitberg, and J. Martínez-Fernández, "The added-value of remotelysensed soil moisture data for agricultural drought detection in argentina," IEEE Journal of Selected Topics in Applied Earth Observations and Remote Sensing, vol. 14, pp. 6487-6500, 2021.

[10] Y. Cai, K. Guan, D. Lobell, A. Potgieter, S. Wang, J. Peng, T. Xu, S. Asseng, Y. Zhang, L. You, et al., "Integrating satellite and climate data to predict wheat yield in australia using machine learning approaches," Agricultural and forest meteorology, vol. 274, pp. 144-159, 2019.

[11] R. Tibshirani, "Regression shrinkage and selection via the lasso," Journal of the Royal Statistical Society: Series B (Methodological), vol. 58, no. 1, pp. 267-288, 1996.

[12] MAGyP, "Office for the monitoring of agricultural emergencies and disasters." https://www.agroindustria.gob.ar/sitio/areas/d_eda/resoluciones/.

[13] INDEC, “Censo nacional agropecuario.” https://www.indec.gob.ar/ftp/ cuadros/economia/cna2018_resultados_preliminares.pdf, 2018.

[14] G. y. P. M. Ministerio de Agricultura, "Office of agricultural statistics." http://datosestimaciones.magyp.gob.ar/reportes.php?reporte= Estimaciones, 2021

[15] C. Funk, P. Peterson, M. Landsfeld, D. Pedreros, J. Verdin, S. Shukla, G. Husak, J. Rowland, L. Harrison, A. Hoell, et al., "The climate hazards infrared precipitation with stations - a new environmental record for monitoring extremes," Scientific data, vol. 2, no. 1, pp. 1-21, 2015.

[16] W. Dorigo, W. Wagner, C. Albergel, F. Albrecht, G. Balsamo, L. Brocca, D. Chung, M. Ertl, M. Forkel, A. Gruber, et al., "Esa cci soil moisture for improved earth system understanding: State-of-the art and future directions," Remote Sensing of Environment, vol. 203, pp. 185-215, 2017.

[17] A. Gruber, T. Scanlon, R. van der Schalie, W. Wagner, and W. Dorigo, "Evolution of the esa cci soil moisture climate data records and their underlying merging methodology," Earth System Science Data, vol. 11, no. 2, pp. 717-739, 2019.

[18] T. Carlson, "An overview of the" triangle method" for estimating surface evapotranspiration and soil moisture from satellite imagery," Sensors, vol. 7, no. 8, pp. 1612-1629, 2007.

[19] S. Khaki, H. Pham, and L. Wang, "Simultaneous corn and soybean yield prediction from remote sensing data using deep transfer learning," Scientific Reports, vol. 11, no. 1, pp. 1-14, 2021. 